DOI: 10.17805/trudy.2017.3.4

\title{
ХАРАКТЕРОЛОГИЧЕСКИЕ ОСОБЕННОСТИ СТАРШИХ ПОДРОСТКОВ, СКЛОННЫХ К КОМПЬЮТЕРНО-ИГРОВОЙ ЗАВИСИМОСТИ
}

\author{
Н. В. Гребенникова \\ Московский гуманитарный университет
}

Аннотация: В статье представлены результаты эмпирического исследования взаимосвязи выраженности зависимости от компьютерных игр у старших подростков и особенностей их эмоционально-личностной сферы.

Ключевые слова: интернет-зависимость; старшие подростки; акцентуации характера; компьютерные игры; Интернет

\section{CHARACTER PECULIARITIES OF LATE ADOLESCENTS PRONE TO COMPUTER GAMES ADDICTION}

\author{
N. V. Grebennikova \\ Moscow University for the Humanities
}

\begin{abstract}
The paper represents the results of an empirical study of the interrelation between the degree of late adolescents' addiction to computer games and peculiarities of their emotional and personal spheres.
\end{abstract}

Keywords: Internet addiction; late adolescents; character accentuations; computer games; Internet

Интернет-зависимость трактуется нами как зависимость от Интернета как глобального средства общения, развлечений, совершения покупок, получения информации и т. д. При этом, как отмечает М. Гриффитс, «индивидуум способен оказаться вовлеченным в применение онлайновых средств в столь высокой степени, что при этом страдают другие стороны его или ее жизни» (Гриффитс, 2009: 253).

Самая первая классификация различных видов интернет-зависимости, созданная К. Янг в 1998 г., включала в себя пять типов: компьютерная зависимость, куда она отнесла пристрастие к компьютерным играм, программированию и другим видам деятельности с компьютером; компульсивные навигаторы сети; перегруженность информацией; киберкоммуникативная зависимость и кибер-сексуальная зависимость (Young, 1998).

М. Гриффитс описывает два вида зависимости: пассивные, такие, как просмотр телепрограмм и активные, например, компьютерные игры) 
(Гриффитс, 2009). В отечественной психологии одной из самых подробных типологий интернет-зависимости можно считать классификацию, предложенную А. Ю. Егоровым (Егоров, 2007). В соответствии с этим подходом можно говорить о существовании среди интернет-аддиктов интернет-гемблеров, интернет геймеров, интернет-трудоголиков, интернет-сексоголиков, интернет-эротоголиков, интернет-покупателей и интернет-аддиктов отношений.

В настоящее время в литературе широко обсуждается проблема, связанная с тем, можно ли приравнивать интернет-аддикцию к психическому расстройству по аналогии с уже известными химическими аддикциями. Дело в том, что, как справедливо отмечает В. Д.Менделевич «Интернетаддикция может рассматриваться как пример уникальной зависимости. Ее спектр распространяется от адекватной привязанности, увлечения, способствующего творческому или душевному самосовершенствованию, и способа компенсации проблем до расстройств зависимого поведения, приводящих к психосоциальной дезадаптации» (Менделевич, 2009: 58).

Несмотря на то, что, по мнению ряда авторов (Егоров, 2007; Войскунский, 2009; Малыгин, Хомерики, Смирнова, 2009), интернет-зависимость не обладает аддиктивной природой в строгом смысле и не включается в современные классификации аддиктивного поведения, в специальной психологической и медицинской литературе подробно описаны многочисленные негативные последствия, которые возникают у человека по мере углубления интернет-зависимости. K наиболее часто выявляемым проблемам психического здоровья и социальной адаптации относят ощущение депрессии, раздражения, пустоты вне занятий с компьютером, пренебрежение семьей и друзьями, проблемы с учебой и работой, а также ряд соматических симптомов (Лоскутова, 2009). У интернет-зависимых также выявляется более высокий уровень аффективных и обсессивнокомпульсивных расстройств с повышенным риском суицида, синдром дефицита внимания с гиперактивностью (Егоров, 2007; Менделевич, 2009; Малыгин, Хомерики, Смирнова, 2009 и др.). Очень тревожным является тот факт, что у интернет-зависимых отмечается коморбидность со злоупотреблением алкоголем, наркотиками или другими веществами, влияющими на изменение сознания. Так по данным А. Ю. Егорова риск наркотизации у интернет-аддиктов оказался в 6,8 раза, а риск алкоголизации в 7 раз выше, чем у испытуемых контрольной группы (Егоров, 2009). Исследование В. А. Лоскутовой показало, что в группе зависимых более $75 \%$ опрошенных имели опыт злоупотребления алкоголем и наркотическими веществами (Лоскутова, 2009).

Данные о частоте встречаемости интернет-зависимости достаточно противоречивы, что, по-видимому, связано с несогласованностью методик и критериев оценки данного рода зависимости, неоднородностью 
процедур исследования, этническим фактором и другими причинами. Так в странах с развитыми компьютерными технологиями такими, как Гонконг, по данным А. Е. Войскунского в 2004 г. было выявлено 37\% зависимых, среди южнокорейских школьников количество зависимых вместе с группой риска составили 40\% (Войскунский, 2009).

Основную группу риска возникновения интернет-зависимости, по мнению исследователей, представляют люди молодого возраста. Это мнение совпадает и с хорошо известными литературными данными о том, что подростковый и юношеский возраст - это наиболее сензитивные возрастные периоды для возникновения зависимостей от психоактивных веществ. В специально проведенном исследовании В. А. Лоскутовой, выполненном на российской выборке, средний возраст интернет-зависимых составил 21 год (Лоскутова, 2009). Ряд авторов объясняет данную закономерность с одной стороны большой популярностью времяпрепровождения в сети, еще недостаточно развитыми механизмами саморегуляции, характерными для молодежи, а также большей доступностью компьютерных технологий по сравнению с людьми более старшего поколения. Контингент пользователей Интернета неуклонно молодеет. В последнее время и в нашей стране стали появляться работы по изучению интернет-зависимости у младших школьников (Котова, 2009). Обсуждая взаимосвязь возраста и риска возникновения интернет-зависимости, следует отметить данные, полученные в работе В. Л. Малыгина и его коллег, также свидетельствующие о том, что наиболее выраженные признаки зависимости проявляются в раннем подростковом возрасте, а максимально процесс дезадаптации обнаруживается в период юношества и перехода от школьной жизни к обучению в вузе (Малыгин, Хомерики, Смирнова, 2009).

Как известно, одним из распространенных видов интернетзависимости является зависимость от компьютерных игр, которая имеет свою специфику. С. К. Бондарева отмечает, что «занимаясь компьютерной игрой, индивид обретает все возможности виртуального мира: владеет временем, пространством и расположенными в нем объектами, может делать с ними все, что пожелает. Но в отличие от перемещений по интернету, которые могут быть увлекательными сами по себе, компьютерная игра дает индивиду нечто боле существенное, а именно недоступное в физическом мире повседневное удовольствие от легкости достижения значимого результата» (Бондарева, Колесов, 2006: 278). И в этом таится, пожалуй, самая большая опасность увлеченности компьютерными играми, на которую указывают многие авторы - бегство из реального мира в виртуальный (там же; Войскунский, 2009), «растворенность» в пространстве Интернета, «ощущение огромных возможностей при минимальных физических действиях - сильное искушение» (Лисецкий, Березин, Козлов, 2009: 142). 
Одной из возможных предпосылок возникновения компьютерноигровой зависимости у подростков наряду с многочисленными микро- и макро-социальными факторами (Малыгин, Хомерики, Смирнова, 2009; Гребенникова, 2014) являются особенности их эмоционально-личностной сферы. Роли личностно-характерологических особенностей в формировании данного типа зависимости у подростков посвящена обширная психологическая литература (Мехтиханова, 2008; Козлов, Карпов, 2011, Егоров, 2007 и др.), содержащая анализ особенностей эмоциональной сферы, проявлений признаков алекситимии, регулятивных механизмов, копинг-стратегий, психологических защит, акцентуаций характера и т.д.

В исследовании, проведенном А. Ю. Егоровым с коллегами, показано, что среди интернет-зависимых преобладали подростки с шизоидным (29,8\%), истероидным (19,3\%), лабильным и эпилетоидным (по 12,3\%) типами акцентуации характера. Реже встречались неустойчивые и психастенические типы личности (по 7\%) и в редких случаях астеноневротические (5,3\%). Результаты исследования по методике Дембо-Рубинштейн продемонстрировали также более низкий уровень самооценки у интернетаддиктов по сравнению с подростками контрольной группы (Егоров, 2007).

Согласно исследованиям В. Л. Малыгина и его коллег, посвященным изучению личностных особенностей подростков, склонных к интернетзависимости, у них были выявлены выраженные тенденции к поиску новых ощущений, менее компетентный по сравнению с контрольной группой стиль общения, эмоциональная отчужденность, снижение способности управлять эмоциями и настроениями, неустойчивость эмоциональных проявлений, конформность поведения, зависимость от группы, низкая стрессоустойчивость, склонность к чувству вины (Малыгин, Хомерики, Смирнова, 2009).

Сравнительный анализ особенностей личности интернет-аддиктов и испытуемых контрольной группы, проведенный М. С. Родионовой и Т.С.Спиркиной, выявил преобладание у первых таких черт личности, как тревожность, эмоциональная неустойчивость, низкий самоконтроль, робость, более высокий уровень депрессии, предпочтение таких копингстратегий, как «бегство-избегание» и «принятие ответственности» (Родионова, Спиркина, 2009).

Целью нашего исследования, которое было проведено в апреле 2016 г. в Москве, было изучение взаимосвязи характерологических особенностей старших подростков и степени выраженности склонности к зависимости от компьютерных игр. В исследовании приняли участие 51 учащийся 10-11 классов (22 девочки и 29 мальчиков) одной из московских общеобразовательных школ в возрасте 16-18 лет.

В качестве основных методик были использованы тест на интернет- 
аддикцию Т. А. Никитина, Ю. А. Егорова (Егорова, 2007) и опросник Шмишека.

Исследование учащихся с целью выявления у них игровой зависимости показало, что $12 \%$ школьников имеют сформированную компьютерноигровую аддикцию, 51\% - входит в группу риска и у $37 \%$ не выявлено каких-либо признаков аддикции.

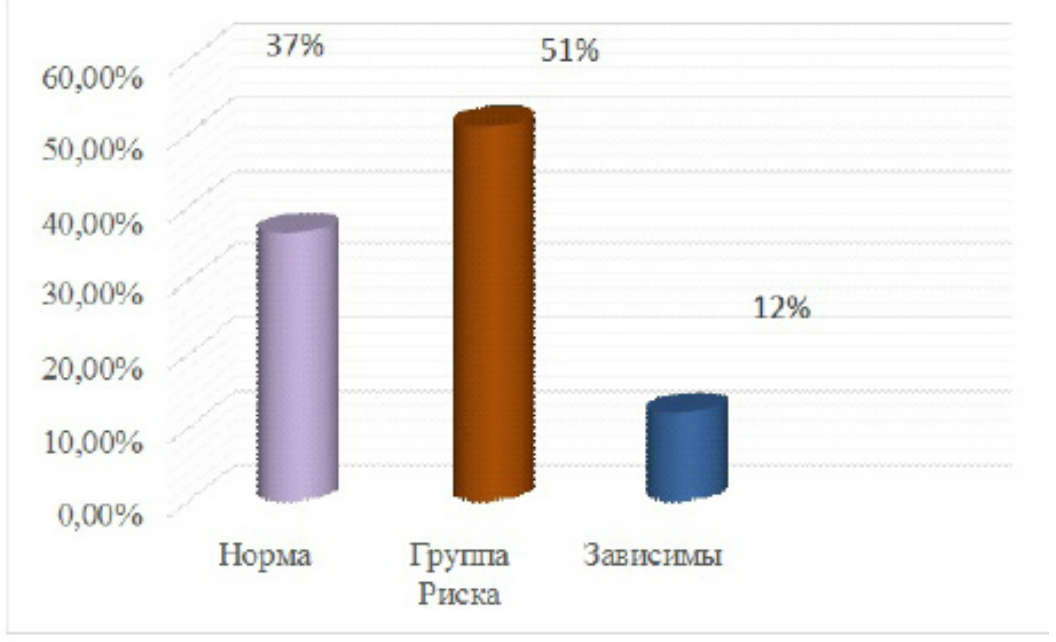

Рисунок 1. Распределение подростков по степени выраженности игровой зависимости.

Анализ мотивов обращения старшеклассников к компьютерным играм позволил выявить следующую картину: 58\% обследованных подростков проводят время за играми для того, чтобы расслабится, $18 \%$ учеников хотят испытать «выброс адреналина», 16\% - почувствовать себя победителем, 8\% - уйти от реальности. Т. о., как следует из отчетов обследованных нами старших подростков, в большинстве случаев они обращаются к компьютерным играм скорее для развлечения, нежели с целью уйти от реальной действительности. Возможно, данные результаты отражают тот период возрастной динамики формирования зависимости, описанной В. Л. Малыгиным с соавторами, когда период наибольшей выраженности ее проявлений, характерный для раннего подросткового возраста, уже закончился, а максимальный процесс дезадаптации, свойственный периоду юношества и перехода от школьной жизни к обучению в вузе, еще не наступил (Малыгин, Хомерики, Смирнова, 2009).

На рис. 2 и 3 представлены результаты анализа того, сколько часов в день школьники проводят за играми, а также, каким играм они отдают большее предпочтение. 


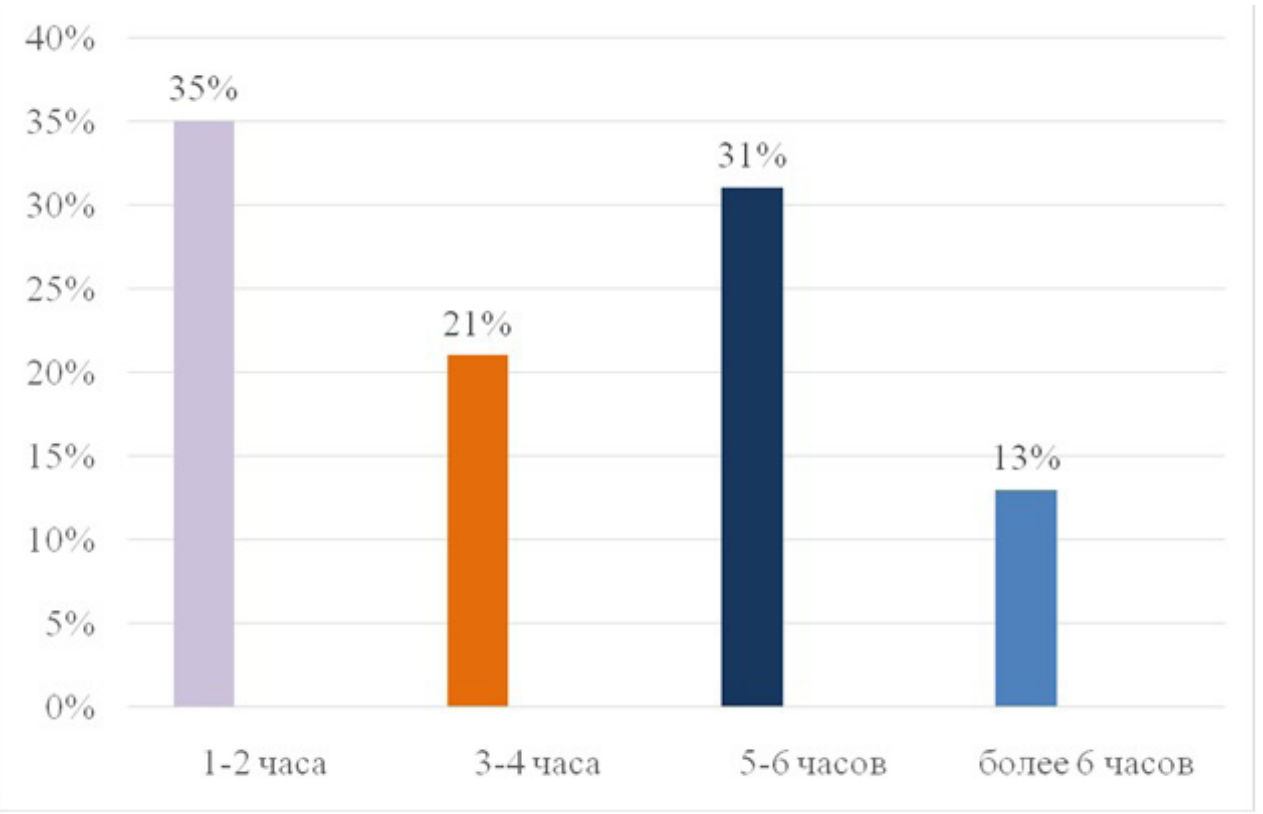

Рис. 2. Распределение подростков по длительности времени, проводимого за игрой.

Полученные данные свидетельствуют о том, что большинство подростков (35\%) проводит за играми в течение дня 1-2 часа, примерно столько же (31\%) - 5-6 часов, 3-4 часа $-21 \%$ и более 6 часов - $13 \%$ школьников.

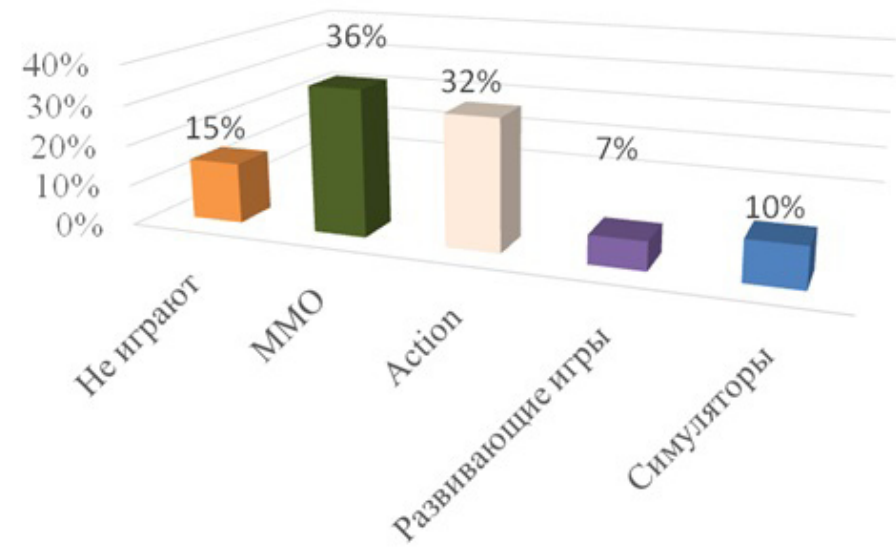

Рисунок 3. Распределение подростков по предпочтению типа компьютерных игр

Анализ предпочтений типов компьютерных игр показывает, что больше всего подростков (36\%) играют в игры типа ММО (массовые многопользовательские он-лайн игры). Это самый популярный жанр видеоигры. Сущность данного жанра состоит в том, что игра практически бесконечна. Выполнив определенное сюжетное задание, игрок может продолжить путь в видеоигре, развивая своего персонажа, или банального нахождения в виртуальной реальности наравне с другими игроками. 
Этот факт можно расценивать как один из определяющих факторов формирования игровой зависимости, поскольку данные видеоигры не имеют финала. В психологическом аспекте у подростков формируется состояние незавершенных действий. Таким образом, подросток возвращается к игре всё чаще и чаще.

Немного меньше (32\%) испытуемых предпочитают такой жанр компьютерных игр, как action. Данный жанр характеризуется тем, что подавляющее количество игр этого типа выпускается для взрослой аудитории. Видеоигры в жанре асtion могут содержать насильственные сцены, ненормативную лексику, тем самым развивая у подростка такие негативные личностные особенности, как агрессивность. 14\% обследованных школьников предпочтение отдают играм-стимуляторам, т. е. таким, которые имитируют управление каким-либо процессом, аппаратом или транспортным средством, и только 7\% подростков предпочитает развивающие игры.

В начале исследования мы предположили, что мальчики имеют большую предрасположенность к игровой зависимости, чем девочки. Не выявлено даже на уровне тенденции наличие игровой зависимости у $25 \%$ мальчиков и 53\% девочек. К группе риска принадлежат 58\% мальчиков и $41 \%$ девочек. У $12 \%$ мальчиков и 6\% девочек обнаружена сформированная игровая зависимость (рис. 4). Т. о., наше исследование подтвердило наличие большей склонности к формированию игровой зависимости у мальчиков по сравнению с девочками.

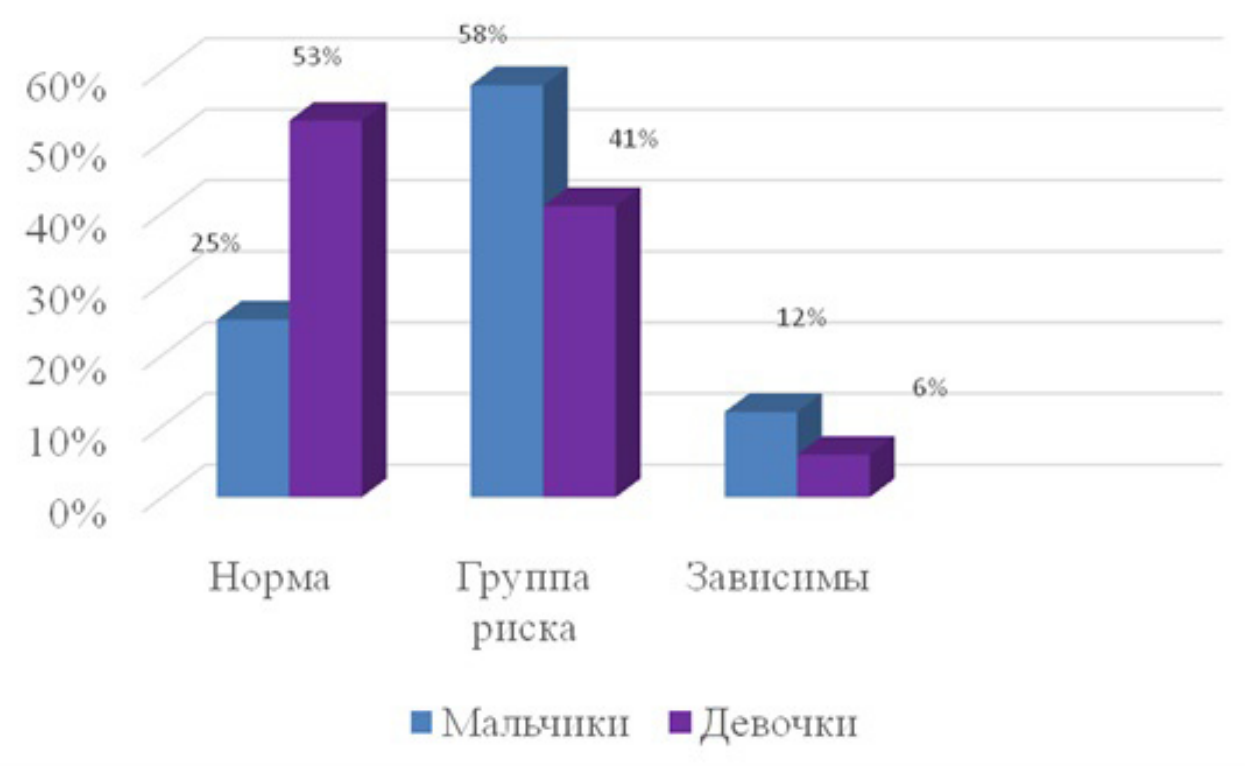

Рис. 4. Частота проявления игровой зависимости у мальчиков и девочек.

Та же закономерность обнаруживается и при анализе длительности времени, проводимого за играми. Оказалось, что минимальное количество времени (1-2 часа) в день за игрой проводят 20\% мальчиков и 50\% 
девочек, 3-4 часа - 30\% мальчиков и 30\% девочек, 5-6 часов - 30\% мальчиков и $20 \%$ девочек и более 6 часов за игрой проводят 20\% мальчиков (рис. 5).

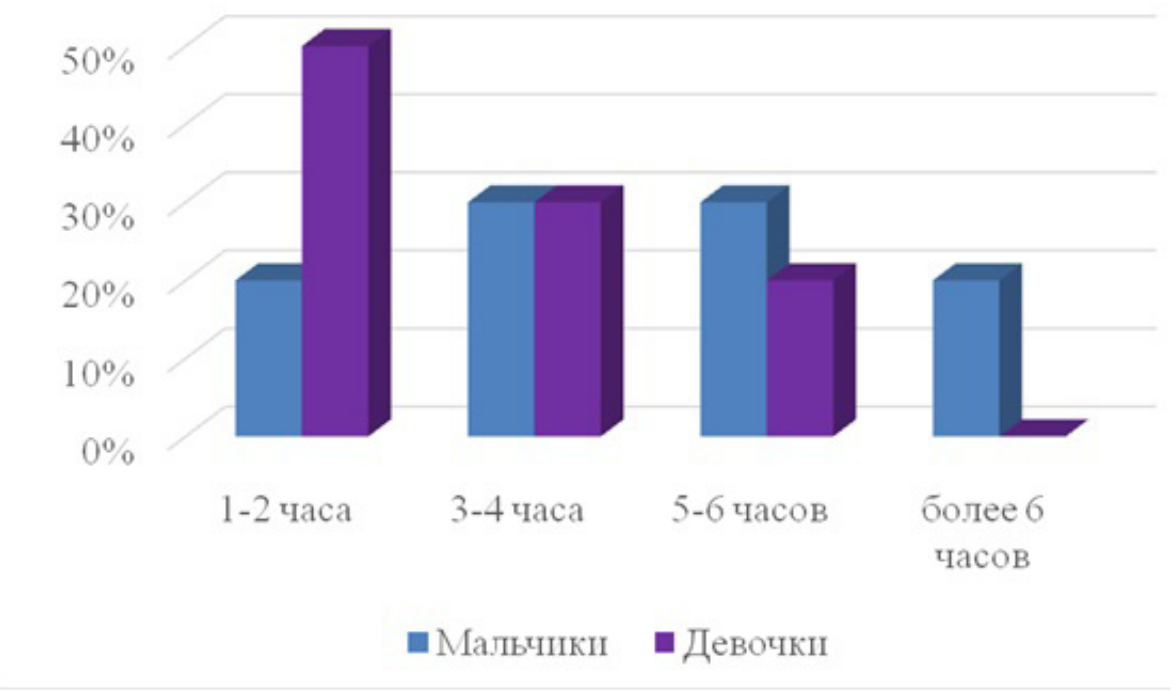

Рис. 5. Распределение мальчиков и девочек по длительности времени, проводимого за игрой.

Относительно жанровых предпочтений можно сказать, что если мальчики в основном предпочитают игры ММО и action (соответственно 45 и 17\%; 37 и 17\%), то девочки отдают предпочтение развивающим играм и играм-стимуляторам (соответственно 11 и 4\%; 11 и 8\%).

Таким образом, сравнительный анализ склонности к компьютерноигровой аддикции в зависимости от половой принадлежности продемонстрировал, что в целом мальчики гораздо больше времени проводят за компьютерными играми, нежели девочки, при этом предпочитаемый жанр игр у мальчиков - MМО, который с большей вероятностью формирует зависимость. Тест на интернет-аддикцию показал, что больше половины девочек из выборки относятся к группе, не имеющей никаких признаков зависимости, в свою очередь значительная часть мальчиков относится к группе риска или уже имеет сформированную зависимость от компьютерных игр.

Полученные данные о взаимосвязи зависимости от компьютерных игр и половой принадлежности в некоторой степени подтверждаются работами израильских исследователей (Hamburger, Ben-Artzi, 2000), на которых ссылается А. Ю.Егоров (Егоров, 2009), и в которых было показано, что если мужчины, особенно с выраженной экстраверсией, предпочитают использовать интернет для развлечения, то женщины в случае проявлений нейротизма чаще используют информационные ресурсы интернета или для общения в чатах.

Проведенный корреляционный анализ дал возможность ответить 
на вопрос о связи проявлений склонности к компьютерно-игровой аддикции у старших подростков с особенностями их характера. Значимые коэффициенты корреляции были обнаружены между выраженностью игровой зависимости и следующими типами акцентуации характера: гипертимность $(\mathrm{r}=0,485 ; \mathrm{p}<0.01)$, эмотивность $(\mathrm{r}=0,314 ; \mathrm{p}<0.01)$, тревожность $(\mathrm{r}=0,336 ; \mathrm{p}<0.01)$, возбудимость $(\mathrm{r}=0,353 ; \mathrm{p}<0.01)$.

Таким образом, по результатам проведенного исследования можно выделить два противоположных типа личности, которые могут представлять группу риска формирования зависимости от компьютерных игр у старших подростков. Первый тип связан прежде всего с такими чертами характера, как постоянно повышенный фон настроения в сочетании с жаждой деятельности, высокая активность, импульсивность, ослабление контроля над влечениями и побуждениями. Второй тип отражает наличие склонности к страхам, повышенную робость, пугливость, высокий уровень тревожности, впечатлительность, глубину переживаний в области тонких эмоций. Если относительное преобладание гипертимов и возбудимых акцентуантов среди зависимых подростков по всей видимости связано с фрустрированностью их потребности в активности и общении в реальном мире, то у второй группы подростков, представленной эмотивными и тревожными акцентуантами, зависимость от компьютерных игр, вероятно, в большей степени обусловлена гиперкомпенсацией, поскольку уход в компьютерную игру позволяет им снизить уровень тревоги, повысить самооценку за счет иной структуры деятельности, выступающей в качестве психологической защиты.

Выявление описанных типов личности, которые можно считать своего рода предикторами возникновения компьютерно-игровой зависимости у старших подростков, в определенной степени можно объяснить, сославшись на так называемую гипотезу дефицитарности (Белинская, 2009), которая наряду с гипотезой комлементарности используется для объяснения феномена интернет-аддикции. Согласно гипотезе дефицитарности реальность инернет-коммуникации восполняет некоторые «дефициты» современного человека, которые фрустрированы социальной реальностью. В русле данной гипотезы выделяется три основные потребности: потребность в стимуляции (гипотезы вознаграждений), потребность в поиске новых ощущений (гипотезы новизны), потребность в безопасности (гипотезы поддержки).

Исследование старших подростков в контексте проблемы зависимости от компьютерных игр позволило сделать следующие выводы:

1. Исследование склонности старших подростков к компьютерноигровой зависимости выявило достаточно тревожную тенденцию, которая проявляется в том, что большая часть обследованных подростков 
(51\%) оказались в группе риска по формированию аддикции, а у $12 \%$ подростков аддикция была уже полностью сформирована;

2. Наиболее частыми мотивами вовлечения старшеклассников в компьютерные игры, являются желание расслабиться, испытать возбуждение, почувствовать себя победителем, в наименьшей степени - уйти от реальности;

3. Выявлены наиболее предпочитаемые жанры компьютерных игр, в которые играют старшие подростки: это массовые многопользовательские ролевые он-лайн игры и игры по типу action, усиливающие риск возникновения зависимости благодаря эффекту незаконченного действия; оказалось, что в наименьшей степени подростков привлекают развивающие игры;

4. Сравнение особенностей формирования игровой аддикции в зависимости от половой принадлежности выявило достоверно большую ее выраженность у мальчиков по сравнению с девочками. Также различия обнаруживались в том, что мальчики и девочки предпочитали разные типы игр: если мальчики больше увлекались массовыми многопользовательскими ролевыми он-лайн играми, то девочки как правило отдавали предпочтение развивающим играм;

5. Результаты корреляционного анализа позволили высказать предположение о том, что склонность к зависимости от компьютерных игр выражена в большей степени у тех подростков, у которых имеют место такие акцентуации характера, как гипертимность, эмотивность, тревожность и возбудимость.

\section{СПИСОК ЛИТЕРАТУРЫ}

Белинская, Е. П. (2009) Взаимосвязь Интернет-зависимости и стратегий совладания с трудными жизненными ситуациями // Интернетзависимость. Психологическая природа и динамика развития / под ред. А. Е. Войскунского. М. : Акрополь. С. 188-199.

Бондырева, С. К., Колесов, Д. В. (2006) Наркотизм. Природа и преодоление. М.: Издательство Московского психолого-социального института ; Воронеж : Издательство НПО «Модек». 431 с.

Войскунский, А. Е. (2009) Методологические аспекты зависимости от интернета // Интернет-зависимость. Психологическая природа и динамика развития / под ред. А. Е. Войскунского. М. : Акрополь С. 101-113.

Гребенникова, Н. В. (2014) Психология аддиктивной семьи // Психология семьи / под ред. Е. Г. Сурковой. М. : Академия. С. 203-229.

Гриффитс, М. (2009) Избыточное применение интернета: онлайновое аддиктивное поведение // Интернет-зависимость. Психологическая при- 
рода и динамика развития / под ред. А. Е. Войскунского. М. : Акрополь. С. 253-257.

Егоров А. Ю. (2007) Нехимические зависимости. СПб. : Речь. 190 с.

Егоров А. Ю. (2009) Интернет-зависимости // Интернет-зависимость. Психологическая природа и динамика развития / под ред. А. Е. Войскунского. М. : Акрополь. С. 29-56.

Козлов, В. В., Карпов, А. А. (2011) Психология игровой зависимости. М. : Психотерапия. 333 с.

Котова, С. А. (2009) Ребенок в новом информационном пространстве // Интернет-зависимость. Психологическая природа и динамика развития / под ред. А. Е. Войскунского. М. : Акрополь. С. 223-237.

Лисецкий, К. С., Березин, С. В., Козлов, Д. Д. (2009) Психологические аспекты Интернет-зависимости: из ИнтерНет в ИнтерДа) // Интернетзависимость. Психологическая природа и динамика развития / под ред. А. Е. Войскунского. М. : Акрополь. С. 138-152.

Лоскутова, В. А. (2009) Интернет-зависимость в медицинской парадигме) // Интернет-зависимость. Психологическая природа и динамика развития / под ред. А. Е. Войскунского. М. : Акрополь. С. 152-165.

Малыгин, В. Е., Хомерики, Н. С., Смирнова, Е. А. (2009) Личностнохарактерологические и социальные факторы риска формирования склонности к Интернет-зависимости у подростков // Интернет-зависимость. Психологическая природа и динамика развития / под ред. А. Е. Войскунского. М. : Акрополь. С. 199-211.

Менделевич В. Д. (2009) Интернет-зависимость и Интернетнезависимость (девиантное поведение в пространстве Интернета) // Интернет-зависимость. Психологическая природа и динамика развития / под ред. А. Е. Войскунского. М. : Акрополь. С. 56-70.

Мехтиханова, Н. Н. (2008) Психология зависимого поведения. М. : Флинт. 155 с.

Радионова, М. С., Спиркина, Т. С. (2009) Характеристики личностной и эмоциональной сферы пользователей сети Интернет, склонных к интернет-зависимости) // Интернет-зависимость. Психологическая природа и динамика развития / под ред. А. Е. Войскунского. М. : Акрополь. С. 113-138.

Young, K. S. (1998) Internet addiction: The emergence of a new clinical disorder // CiberPsychology \& Behaviour. Vol. 3. № 1. P. 237-244.

Hamburger,Y.A.,Ben-Artzi,E.(2000)Therelationshipbetween extraversion and neuroticism and the different uses of the Internet // Computers in Human Behaviour. Vol. 16. № 4. P. 441-449.

Дата поступления: 26.05.2017 г. 
Гребенникова Наталия Васильевна - кандидат психологических наук, доцент, профессор кафедры общей психологии и истории психологии Московского гуманитарного университета. Адрес: 111395, Россия, г. Москва, ул. Юности, д. 5. Тел.: +7 (499) 374-67-20. Эл. адрес: grebennikovanataliya@yandex.ru

Grebennikova Natalia Vasilievna, Candidate of Psychology, Professor, Department of General Psychology and the History of Psychology, Moscow University for the Humanities. Postal Address: 5, Yunosti St., Moscow, Russian Federation 111395.Tel.: + 7 (499) 374-67-20.E-mail: grebennikovanataliya@ yandex.ru

\section{Для циитирования:}

Гребенникова Н. В. Характерологические особенности старших подростков, склонных к компьютерно-игровой зависимости [Электронный ресурс] //Научные труды Московского гуманитарного университета. 2017, № 3. URL: http://journals.mosgu. ru/trudy/article/view/498 (дата обращения: дд.мм.гг.). DOI: 10.17805/trudy.2017.3.4 